\title{
The Effect of EFL Teachers' Extrovert and Introvert Personality on Their Instructional Immediacy
}

\author{
Amir Mahdavi Zafarghandi \\ English language Teaching Department, Faculty of Humanities, University of Guilan, Iran \\ E-mail: mahdavi1339@gmail.com \\ Sepideh Salehi (Corresponding author) \\ English Language Teaching Department, University of Guilan, Campus 2, Iran \\ E-mail: sepide.salehi@gmail.com \\ Masoud Khalil Sabet \\ English Language Teaching Department, Faculty of Humanities, University of Guilan, Iran \\ E-mail: sabetma2002@yahoo.com
}

\author{
Received: 16-05-2015 \\ Accepted: 27-08-2015 \\ Advance Access Published: October 2015 \\ Published: 01-01-2016 \\ doi:10.7575/aiac.ijalel.v.5n.1p.57 \\ URL: http://dx.doi.org/10.7575/aiac.ijalel.v.5n.1p.57
}

\begin{abstract}
The Language teaching is a complex process influenced by many psychological factors such as personality traits (Tonelson, 1981) and socio-communicative styles (Thomas. Et al. 1994). This research sets out to investigate the effect of Teachers' Introvert and Extrovert personality on their instructional Immediacy. In order to address this issue, a study was conducted on $14 \mathrm{PhD}$ holder university EFL lecturers from Guilan province. Instruments for this research included preliminary Myers-Briggs Personality Type Indicator (MBTI) Test, non-verbal immediacy scale, along with verbal immediacy scale observation inventory. After determining the lecturers' Introvert/Extrovert personality, at the next stage, six sessions of direct observation of each lecturer's classroom instructional immediacy were conducted. Statistical analysis of Fisher's exact test between data along with Pearson's correlation was run to determine the relationship between teacher's extrovert personality and their use of verbal immediacy; the results indicate strong, positive correlation $(\mathrm{r}=.7, \mathrm{p}<.03)$. Similarly, a strong, positive correlation was found between extrovert personality and use of non-verbal immediacy $(\mathrm{r}=.75, \mathrm{p}<.01)$. The other finding of the study was that instructors' gender showed no significant relation with their verbal and nonverbal instructional immediacy.
\end{abstract}

Keywords: EFL teachers, Introvert / Extrovert personalities, Verbal and Nonverbal instructional immediacy

\section{Introduction}

Teacher personality and instructional immediacy have been studied independently for decades. Often, effective teacher traits are linked with perceivably unchangeable constructs such as personality (Clayson, 1999). In teacher education, it is important to continue examining ways to identify influential teacher traits and use them to effectively choose and prepare prospective teachers. According to Ali Shah (2009), Teaching can, in fact, be defined as a conscious behavior that makes learning more probable efficient than it would have been without that behavior.

Learning is a process that involves cognitive and social psychological dimensions, and both processes should be considered if learning achievement is to be maximized (Hallinan, 2008). As Polk (2006) argues, teacher performance is influenced by the teachers' personality characteristics. Teachers' abilities to form positive relationships with students are affected by their personality type, experiences, and the quality of their own personal relationships (Baker, 2006). Teachers' ability to increase their understanding of themselves as well as their students is critical in building and maintaining a communicative Teacher-Student relationship. Learners in such a teacher's class are expected to possess positive attitudes toward learning and display more interaction with others. Increased interaction among learners, in return, positively affects their perceptions of social presence, acknowledging others as real individuals (Hackman \& Walker, 1990). Personality could also be regarded as one of the predictors in evaluating teaching effectiveness, eventually maximizing achievement in language learning.

\subsection{Research Questions}

Within this framework, this study aims to determine whether teachers' introvert or extrovert personality, in fact, affects their instructional immediacy. Furthermore, this study will compare the corresponding gender differences in this regard. To be more specific, the current study investigates the following research questions:

Is there any significant relation between Introvert or Extrovert personality and EFL teachers' Verbal immediacy?

Is there any significant relation between Introvert or Extrovert personality and EFL teachers' nonverbal immediacy? 
Is there any significant relation between gender and EFL teachers' Verbal immediacy?

Is there any significant relation between EFL instructors' gender and their non-verbal immediacy?

Teachers' personality and instructional immediacy are among important issues in the process of language teaching. Palmer (1998) states, it is important "to understand my own nature as a teacher and to learn the techniques that might help it along” (p. 24). Sperber (2005) concurs with Palmer noting that one should teach according to one's personality, not the trend of the day, mentors, or anyone else. It is important to determine if teacher's introvert / extrovert personality is indeed a factor in raising student achievement. Therefore, considering them and conducting research like the current one on the relationship between them could help language teachers be more efficient in the process of language teaching. In other words, by taking into account these factors, not only the Ministry of Education, but also teachers themselves would become aware of the importance of certain teaching qualities and instructional behaviors so that students may be the ultimate beneficiaries. An important point worth mentioning is that, to the best of our knowledge, this is the first time these two variables will be merged into one study in the Iranian educational context.

\subsection{Background}

\subsubsection{Personality}

Carl Jung (1921) first developed the theory that individuals each had a psychological type. The theory of Personality types contends that our innate Personality type indicates how we are likely to deal with different situations that life presents, and in which environments we are most comfortable. Miller (1991), in contrast, suggests that there is a serious problem inherent in these concepts, where personality is believed by some to be a fluid construct instead of an innate definition by which the individual is regarded as a person. Miller (1991) also emphasizes that it is important that personality types are not identified as a definitive streamlining system that can effectively pigeonhole various individuals into ideal educational, professional, and life scenarios. Rather, it is important to take other issues into consideration, He notes that it must be recognized that there is a distinction between "intelligence" and "personality," where the abilities and the potential inherent within an individual are often confused in respect to their significance (ibid.). It should be noted that we cannot label individuals for default and prescribed formulas of behavioral traits. However, we can identify ones' natural preferences, and learn about their natural strengths and weaknesses within the desired context.

\subsubsection{Extroversion and Introversion}

Extroversion means "outward-turning" and introversion means "inward-turning" (Zeisset, 2006). These specific definitions vary somewhat from the popular usage of the words. The preferences for extraversion and introversion are often called attitudes. Each of the cognitive functions can operate in the external world of behavior, action, people, and things (extroverted attitude) or the internal world of ideas and reflection (introverted attitude). People who prefer extroversion draw energy from action: they tend to act, then reflect, then act further. If they are inactive, their motivation tends to decline. To rebuild their energy, extroverts need breaks from time spent in reflection (ibid.). Conversely, those who prefer introversion expend energy through action: they prefer to reflect, then act, then reflect again. To rebuild their energy, introverts need quiet time alone, away from activity. The extrovert's flow is directed outward toward people and objects, and the introvert's one is directed inward toward concepts and ideas. Contrasting characteristics between extroverts and introverts include the following:

Table 1. Introvert and Extrovert characteristics adapted from Shoarinejad (1984)

\begin{tabular}{ll}
\hline Extroversion & Introversion \\
- Show more attention and interest toward people and & - Show more attention to their thoughts and feelings. \\
objects. & - Concerned about the future and provides. \\
- Live in the present. & - Usually conservative. \\
- Usually radical. & - Hold the application of principles and criteria more \\
- Hold the actions and their results as more important. & important. \\
- Smooth speakers. & - Better writers than speakers. \\
- Interested in sports and physical activities. & - Interested in books and magazines. \\
- Tangible world and its phenomena are considered & - Consider mental or subjective factors of more value. \\
more important. & - Spend more time planning and analyzing, then taking \\
- Make decisions fast and execute them quickly. & action. \\
- Friendly and very sociable. & - Unsociable. \\
- Consider objective factors of more value. & \\
\hline
\end{tabular}

\subsubsection{Instructional immediacy}

Instructional immediacy is such a behavior that brings the instructor and the students closer together in terms of perceived distance (Mehrabian, 1969). Immediacy is the perception of physical and psychological closeness between 
communicators. As Chory \& McCroskey (1999) state, teacher immediacy has a tremendous impact on the learning of the students. As immediacy increases, so do the positive perception of learning itself. The course material becomes ties to the teacher. Thus, the judgment of the teacher via immediacy is projected onto the course material. Social psychologist, Dr. Mehrabian, has been credited with defining the concept of immediacy in terms of his "principle of immediacy," derived from Mehrabian's (1969) study, i.e. immediacy is conceptualized as those nonverbal behaviors that reduce physical and/or psychological distance in interpersonal communication. In other words, there are sets of verbal and non-verbal communication behaviors that can reduce the perceived physical or psychological distance between communicators (Witt, Wheeless, \& Allen, 2004). Andersen (1979) demonstrates that the major communicative function of immediacy behaviors is that they reflect a more positive attitude of the sender to the receiver.

\subsubsection{Non-verbal and verbal immediacy}

Arnold (2003) has proposed that the nonverbal cues a person gives off may even be more important than the verbal responses that he/she gives. Non-verbal immediacy behaviors generally involve kinesics, proxemics, vocalics, haptics, and oculesics, but the most noticeable teacher non-verbal immediacy behaviors usually include smiling, vocal variety and expressiveness, eye contact, gestures, touching and relaxed body position (Andersen, 1979). Non-verbal immediacy is related positively to teaching effectiveness, student state motivation, and affective or cognitive learning outcomes (Zhang \& Oetzel, 2006). Much of the research reveals that non-verbal immediacy behavior can be improved through training (Nussbaum, 1984; Richmond \& McCroskey, 2004).

Studies on the teacher verbal immediacy included behaviors such as talking about experiences that have occurred outside class, communicating with learners before and after classes, using humor to attract attention, encouraging learners to actively participate and ask questions, addressing learners by name, praising learners' work or comments, and providing feedback on learners' work. Her results suggest that these types of behavior also contributed significantly to students' affective learning. Depending on the words selected, verbal immediacy serves to improve psychological feeling of closeness among individuals. For example, instead of words like "you" and "me", using the word "us" enhances feelings of closeness and association (Gorham, 1988).

\section{Methods}

\subsection{Participants}

The population of this study consisted of university lecturers at Guilan province, who were PHD holders in the fields of TEFL and English Literature. However, the sample was restricted only to PHD holders in both aforementioned fields.

17 professors gave consent to taking part in the study. After the aims of the study were described and the process of required data collection was explained to them and ensuring the confidentiality of the data gathered through whole study.

After determining the lecturers' Introvert/Extrovert personality, with the aim of having a homogeneous and equal sample, 14 lecturers were chosen. The convenience sample included 14 lecturers, $(\mathrm{N}=14)$, all of whom are EFL PHD holder lecturers from university of Guilan and IAU (Islamic Azad University). The teaching experience mean of the lecturers is $12.25(+0.4 \%)$.

Table 2. Personality distributions of sample

\begin{tabular}{lccc}
\hline & Male & Female & Total \\
\hline Extroversion & 3 & 4 & 7 \\
\hline Introversion & 4 & 3 & 7 \\
\hline Total & 7 & 7 & 14 \\
\hline
\end{tabular}

\subsection{Instruments}

For purposes of the current study, three main instruments were used:

- $\quad$ Myers-Briggs Personality Type Indicator test form M.

- $\quad$ Nonverbal Immediacy Scale-Observer Report (NIS-O) by Richmond.et al. (2003).

- Verbal Immediacy Scale-Observer Report (VIS-O) by J. Gorham, D.M. Christophel, 1990.

Description of instruments:

\section{a. Myers-Briggs Personality Type Indicator test}

One of the most important steps in this research was to determine the personality type of the sample. Myers-Briggs Personality Type Indicator (MBTI) instrument is one of the most widely used personality assessments in the world.

There are many versions of MBTI. For this study, the Myers-Briggs Personality Type Indicator Test form M was chosen. This form of tests is self-scoreable, consisting of 93 items. This form was adopted as its original format and no changes or adaptation of it was made by the researcher.

The Internal Consistency Reliability of MBTI E/I Dichotomy by Ethnic Groups, in multi-ethnic group are 0.91 and in 
Middle Easterners is 0.88. Furthermore, the Test-Retest Correlations by Gender for E/I MBTI Dichotomy is 0.84 for men and 0.72 for women with one year interval (Schaubhut, et al. 2009).

As for the validity, correlations of the MBTI Form $\mathrm{M}$ assessment with six other assessments show expected relationships with these other instruments. Factor analysis shows the expected four-factor structure of the assessment (ibid.).

\section{b. $\quad$ Nonverbal Immediacy Scale-Observer Report (NIS-O)}

The revised version of NIS-O by Richmond is most up-to-date measure of nonverbal immediacy as another observerreport. Alpha reliability estimates around .90 should be expected. This measure has more face validity than previous instruments because it has a greater number of diverse items. Its predictive validity is also high (Richmond.V, et al. 2003).

\section{c. Verbal Immediacy Scale-Observer Report (VIS-O)}

Verbal Immediacy was measured with a Verbal Immediacy Scale consisting of 23 items (J. Gorham, D. M. Christophel, 1990 ) with an alpha reliability of 0.88 . The immediacy questionnaire contained 17 verbal and 6 nonverbal items. Items 19 and 22 were reverse scored, such that higher numbers indicated more immediacy.

\subsection{Procedures}

\subsubsection{Data Preparation procedure}

The primary data by the means of Myers-Briggs Type Indicator; was collected from 17 EFL PhD holder university lecturers. Utilizing MBTI form M, which includes 93 forced-choice items, meaning that the individual has to choose only one of two possible answers to each item. The choices are a mixture of word pairs and short statements. Choices are not literal opposites but chosen to reflect opposite preferences on the same dichotomy. Using psychometric techniques, such as item response theory, explained in the self-score able pamphlet of form M, the MBTI were then scored, trying to identify the preference as well as the clarity of preference in each dichotomy. After applying MBTI test, personalities were determined, purposefully having a homogeneous and equal sample, i.e. 14 lecturers, 7 men and 7 women were chosen.

During six weeks, six direct observation sessions of each lecturer's instructional behavior was conducted in their classrooms in order to assess their verbal and non-verbal immediacy according to the observers' report checklist, formerly introduced in the instrumentation.

\subsubsection{Data analysis procedure}

Descriptive statistics has been applied. Data in this study are non-parametric and due to the categorization of data scores as frequencies the Pearson Chi square analysis was used to test each one of the 4 hypotheses by applying the Fisher exact test for independence of the sample data, computing the degrees of freedom, the expected frequency counts, and the chi-square test statistic. After collecting the data, they were coded and labeled ( 1 for female; 2 for male, for example) and scored in an organized fashion for easy tabulation. By act of coding, the scale measures were turned into nominal. Due to the size of the sample the frequencies were counted and applied to Chi square test for fisher exact test to examine whether there are statistically significant differences in instructional immediacy of each personality group.

\section{Results}

In this study the most prominent finding was that Extrovert personality does, in fact, show a relationship with instructional Immediacy $(r=.7, r=.75)$. The analyses displayed how instructors with different extrovert and introvert personalities appear to use different aspects of instructional immediacy. The other finding was that instructors' gender had little or very weak correlation with their use of verbal and nonverbal instructional immediacy $(r=-.2, r=-.23)$.

The results are presented step by step in relation to the research questions. To answer the research questions, Pearson chi-square was conducted.

Answer to the first question has shown that there is a significant difference between teachers' use of verbal immediacy according to their personality $(\mathrm{r}=.7)$. Proportional differences of personality over verbal instructional immediacy with fisher exact test calculated value (6.805) was shown to be statistically significant $(\mathrm{p}<.03)$. This means that extroverted teachers used verbal instructional immediacy more frequently at a statistically significant level (cf. Table 3a).

Answer to the second question has similarly showed that there is a significant difference between teachers' use of nonverbal immediacy according to their personality $(\mathrm{r}=.75)$. Proportional differences of personality over non-verbal instructional immediacy with fisher exact test calculated value (7.498) was shown to be statistically significant ( $p<.01)$. This means that extroverted teachers used non-verbal instructional immediacy more frequently at a statistically significant level (cf. Table 3b).

Answer to the third question based on direct observations shows no significant difference between instructors' gender and their use of verbal immediacy at .05 level of significance (fisher exact test value, 1.178). That is, gender of teachers had no significant relation with their verbal instructional immediacy performance (cf. Table $3 \mathrm{c}$ ).

Answer to the forth question based on direct observations shows that there is no significant difference between instructors' gender and their use of non-verbal immediacy at .05 level of significance (fisher exact test value, 1.506) Therefore, instructors' gender had little or no notable effect on their non-verbal instructional immediacy performance (cf. Table 3d). 
Table 3a. Personality and verbal immediacy Fisher exact test

\begin{tabular}{lccccc}
\hline & Value & df & $\begin{array}{c}\text { Asymp. Sig } \\
(2 \text { sided })\end{array}$ & $\begin{array}{c}\text { Exact. Sig } \\
(2 \text { sided })\end{array}$ & $\begin{array}{c}\text { Point } \\
\text { probability }\end{array}$ \\
\hline Pearson Chi-square & 7.238 & 2 & .027 & .029 & \\
\hline Likelihood Ratio & 8.260 & 2 & .016 & .029 & \\
\hline Fisher's Exact Test & 6.805 & & & .029 & .012 \\
\hline $\begin{array}{l}\text { Linear-by-Linear } \\
\text { association }\end{array}$ & 6.158 & 1 & .013 & .025 & \\
\hline N of Valid Cases & 14 & & & &
\end{tabular}

Table 3b. Personality and non-verbal immediacy Fisher exact test

\begin{tabular}{lccccc}
\hline & Value & df & $\begin{array}{c}\text { Asymp. Sig } \\
(2 \text { sided })\end{array}$ & $\begin{array}{c}\text { Exact. Sig } \\
(2 \text { sided })\end{array}$ & $\begin{array}{c}\text { Point } \\
\text { probability }\end{array}$ \\
\hline Pearson Chi-square & 7.905 & 2 & .019 & .013 & \\
\hline Likelihood Ratio & 9.847 & 2 & .007 & .033 & \\
\hline Fisher's Exact Test & 7.498 & & & .013 & .006 \\
\hline $\begin{array}{l}\text { Linear-by-Linear } \\
\text { association }\end{array}$ & 7.262 & 1 & .007 & .013 & \\
\hline N of Valid Cases & 14 & & & & \\
\hline
\end{tabular}

Table 3c. Gender and verbal immediacy Fisher exact test

\begin{tabular}{lccccc}
\hline & Value & df & $\begin{array}{c}\text { Asymp. Sig } \\
(2 \text { sided })\end{array}$ & $\begin{array}{c}\text { Exact. Sig } \\
(2 \text { sided })\end{array}$ & $\begin{array}{c}\text { Point } \\
\text { probability }\end{array}$ \\
\hline Pearson Chi-square & 1.143 & 2 & .565 & 1.000 & \\
\hline Likelihood Ratio & 1.530 & 2 & .465 & 1.000 & \\
\hline Fisher's Exact Test & 1.178 & & & 1.000 & .241 \\
\hline $\begin{array}{l}\text { Linear-by-Linear } \\
\text { association }\end{array}$ & .684 & 1 & .408 & .694 & \\
\hline N of Valid Cases & 14 & & & &
\end{tabular}

Table 3d. Gender and non-verbal immediacy Fisher exact test

\begin{tabular}{lccccc}
\hline & Value & df & $\begin{array}{c}\text { Asymp. Sig } \\
(2 \text { sided })\end{array}$ & $\begin{array}{c}\text { Exact. Sig } \\
(2 \text { sided })\end{array}$ & $\begin{array}{c}\text { Point } \\
\text { probability }\end{array}$ \\
\hline Pearson Chi-square & 1.476 & 2 & .478 & .633 & \\
\hline Likelihood Ratio & 1.530 & 2 & .465 & .633 & \\
\hline Fisher's Exact Test & 1.506 & & & .633 & .157 \\
\hline $\begin{array}{l}\text { Linear-by-Linear } \\
\text { association }\end{array}$ & .807 & 1 & .369 & .551 & \\
\hline N of Valid Cases & 14 & & & & \\
\hline
\end{tabular}

\section{Discussion}

The study has clearly shown that extrovert teachers show superiority over introverts in their overall instructional immediacy performance. Extroverted teachers provide a richer communicative environment that establishes a more productive interaction with the students as their audience. Teaching English language to students by them may be more successful, where the students are the beneficiaries.

In this study, it has also been made clear that instructors with extrovert personalities make more use of verbal 
immediacy in and out of the classroom context than what Introverts do. Similarly, different researches have shown that verbal behaviors are indeed influenced by extrovert personality. For instance, Furham (1990) states that extroverts talk more, faster, louder, and more repetitively than introverts, using fewer pauses and hesitations. Extroverts are less formal and use more positive emotion words and more references to context (Penne baker \& king, 1999). Result of the study also showed that extrovert teachers show superiority over the introvert teachers in their non-verbal instructional immediacy; as they provide a situation full of non-verbal communication such as physical proximity, eye contact, smile, gesture of being receptive to audiences' comments, it would create warm and positive atmosphere. Hence, the students would be strongly motivated to communicate with the instructor and their peers in the target language, i.e. English in this study.

The other findings of the study concerning the relation between gender and instructional immediacy, shows that there are no significant differences in using verbal immediacy between male and female teachers, irrespective of lecturers' status (Gendered social interaction is guided by status, positions people occupy, and roles, the manner associated with a status). However, this finding is in contrast with findings of other scholars, such as Leaper (2007), who states "Men tend to be more talkative than women, but particularly when they're interacting in mixed-gender settings," explaining that this could also be a result of men traditionally being socialized to dominate. Aries (1996) argues, the way in which men and women interact is highly dependent on the situation and reasons for interacting.

Probably, the reason can be inadequacy of our samples; furthermore another explanation for the present results might be due to the decreasing difference gap between two genders' social and professional behaviors especially in an educated generation in Iran.

In addition, the results of this study show that gender cannot be considered as a leading factor in anticipating how much non-verbal communication and instructional immediacy male and female teachers would use. Other studies conducted on fairly different societies, have confirmed that women use more non-verbal immediacy such as eye contact, nodding and touching. Andersen (1999) states that women gesture, make eye contact, touch and stand close to the same-gender of conversational partners, and use smile and positive facial expressions in mix-gender conversations more than men. However, this was not observed in this study. We can relate this finding to our cultural and religious beliefs about women and society. As Payne (2001) emphasizes, Nonverbal communicative behavior is affected by culture. Studies involving the use of space as a part of interpersonal communication recognizes that "people of different cultures do have different ways in which they relate to one another spatially" with spatial use defining social relationships and social hierarchies (ibid). It is important to note that social interaction is a process governed by norms that are largely determined by culture. Cultural norms offer general guidelines for role of verbal and nonverbal behavior. The context of the interaction is usually a key determinant of role performance.

\section{Conclusion}

An idea central to exploring the relation between teachers' personality and their instructional immediacy is the realization that educational programs are important, but the real essence of teaching is carried on in classroom through mutual reciprocity between the instructor and students; hence, efforts should be made to facilitate teaching process as a result of which students would be the beneficiaries. To achieve the goals, we are required to study the individual characteristics and also to be aware of the needs and characteristics of the society; therefore, career guidance and counseling play a critical role in the matter. The concept of career guidance covers the individual's life span and all sorts of professional support and activities that he needs for making well-grounded decisions about his occupation and activities that contribute not only to his personal development but also the society in which he lives and prospers. "An organized activity that helps the individual realize his competencies and trains him to plan the appropriate steps to develop essential skills that will lead to personal, educational, economic, and social advancement for the individual, family, society and nation" (International Association for Educational and Vocational Guidance, 2001). Mansour (1972) also defines career guidance as a way to help the person to choose a job, which is suitable according to their talents, capacities, characteristics and personality.

An important point to consider is that English Language graduates, even if they graduate in English Language Teaching majors, are not necessarily good at teaching the language. Since the final goal in English language teaching is to teach the students how to use the English language effectively and fluently; therefore, English language teachers should prepare themselves by participating in specific teaching courses and improve their teaching methods so that they could be more effective at teaching and successful instructors. Since personality traits influence instructors' behavior and instructional immediacy in the classroom, the way personality traits influence teacher's interactions with students may create a more positive environment for students, resulting not only in more meaningful learning, but also increase their graduation rates and decrease the job burnout rate of teachers.

Nowadays, meritocracy is a major factor in employment. In other words, applicants should be chosen for jobs considering their abilities, characteristics and talents. In fact, they should ideally have the main characteristics required for the targeted job. Since teaching the language requires communication, mutual reciprocation plays a major role in conveying the language teaching materials from instructors to students. This would be an idealistic thought, and practically not possible to recruit the extroverted teachers in language teaching system only, being mindful that much of the research revealed that non-verbal immediacy behavior can be improved through training (Nussbaum, 1984; Richmond \& McCroskey, 2004), with respect to the fact that class management methods and instructional immediacy of extroverted teachers would have more efficiency, their ways of teaching and class management and instructional methods can be taught to other teachers especially introverted teachers in some teacher training courses so they can 
improve their instruction methods prior to teaching the language.

\subsection{Suggestion for further studies}

For conducting future studies, it is recommended:

1. A larger sample should be selected. Therefore, in further studies researchers may survey instructors from language institutes, and language teachers from schools as a result of which the results could be generalizable to a wider language teaching context.

2. In further studies, teaching experience should also be considered as a variable, as this variable may have meaningful implications for language teaching profession.

\section{References}

Ali Shah, S. (2009) Impact of Teacher's Behavior on the Academic Achievement of University Students. PhD thesis, University of Arid Agriculture, Rawalpindi, Pakistan.

Andersen, J. F. (1979). Teacher immediacy as a predictor of teacher effectiveness. Communication Yearbook, 3, 543559.

Andersen, P. (1999), Nonverbal Communication: Forms and Functions, California: Mayfield, 118-21.

Aries, E. (1996). Men and women in interaction: Reconsidering the differences. New York: Oxford University Press.

Arnold, M. (2003). Selling with Emotional Intelligence. Chicago: Dearborn Press.

Baker, J. A. (2006). Contributions of teacher-child relationships to positive school adjustment during elementary school. Journal of School Psychology, 44(3), 211-229.

Board of Directors of IAEVG, (2001). International Association for Educational and Vocational Guidance. Paris.

Chory, R. M., McCroskey, J.C. (1999). The relationship between teacher management, communication style, and affective learning. Communication Quarterly, 47, 1-18.

Clayson, D. E. (1999). Student's evaluation of teaching effectiveness: Some implications of stability. Journal of Marketing Education, 21(1), 68-75.

Furnham, A. (1990). Language and personality. In in W.P. Robinson, and H. Giles (Ed), the New Handbook of Language and Social Psychology. New York: Wiley

Gorham, J. (1988). The relationship between verbal teacher immediacy behaviors and Students learning. Communication Education, 37, 40-53.

Gorham, J., \& Christophel, D. M. (1990). The relationship of teachers' use of humor in the classroom to immediacy and student learning. Communication Education, 30, 46-62.

Hackman, M. Z., \& Walker, K. B. (1990). Instructional communication in the televised classroom: The effects of system design and teacher immediacy on student learning and satisfaction. Communication Education 39 (3): 196-206.

Hallinan, M. T. (2008). Teacher influences on students' attachment to school. Sociology of Education, 81(3), $271-283$. Retrieved from http://dx.doi.org/10.1177/003804070808100303

Leaper. C., \& Ayres. M. (2007). A Meta-Analytic Review of Gender Variations in Adults' Language Use: Talkativeness, Affliative Speech, and Assertive Speech. Personality and Social Psychology Review, 11, 328-363.

Mansour, M. (1972). Introduction to Professional Counseling. Tehran: Atai publication.

Mehrabian, A. (1969). Methods \& designs: Some referents and measures of nonverbal behavior. Behavioral Research Methods and Instrumentation, 1, 203-207.

Mehrabian, A. (2007). Nonverbal Communication. Transaction Publishers.

Miller, A. (1991). Personality types, learning styles and educational goals. Educational Psychology, 11(3/4).

Myers, I.B., Myers, P.B., McCaulley, M., Quenk, N.L \& Hammer, A.L. (1998). MBTI Manual: A guide to the development and use of the. Myers-Briggs Type Indicator. 3rd Ed. Palo Alto, CA: Consulting Psychologists Press.

Palmer, P.J. (1998). The courage to teach: Exploring the inner landscape of a teacher's life. San-Francisco: JosseyBass.

Payne, K. E. (2001). Different but equal: Communication between the sexes. Westport ,CT: Praeger.

Penne baker, J.W., \& King, L.A. (1999). Linguistic styles: language use as an individual difference. Journal of personality and social psychology 77, 1296-1312.

Polk, J. A. (2006). Traits of Effective Teachers. Arts Education Policy Review, 107, 23-30.

Richmond, V. P., McCroskey, J. C., \& Johnson, A. E. (2003). Development of the Nonverbal Immediacy Scale (NIS): Measures of self- and other-perceived nonverbal immediacy. Communication Quarterly, 51, 502-515. Retrieved from www.midss.ie

Schaubhut, N. A., \& Thompson, R. C. (2009, in press-a). Technical brief for the MBTI® Form M and Form $Q$ 
assessments, Mountain View, CA: CPP, Inc.

Shindler, J. V. (1998). Who Gets into Teaching? Cognitive Style as a variable in Predicting Teaching as a Career Choice. ERIC.

Shoarinejad, A. (1984). General Psychology. Tehran: Toos Inc. P.575.

Smith, P. B. 1977. Small Groups and Personal Change. London: Methuen. P.482.

Sperber, M. (2005). Notes from a career in teaching. The Chronicle of Higher Education, p. B20.

Thomas, C. Richmond, V. P. and McCroskey, J. (1994). the Association between Immediacy and Socio-Communicative Style. Communication Research Reports, Vol. 11 Issue 1, p107

Tonelson, S. W. (1981). The Importance of Teacher Self-Concept to Create a Healthy Psychological Environment for Learning. Education 102, 96 - 100.

Witt, P., Wheeless, L., \& Allen, M. (2004). A meta-analytical review of the relationship between teacher immediacy and student learning. Communication Monographs, 71(2), 184-207.

Zeisset, C. (2006). The Art of Dialogue: Exploring Personality Differences for More Effective Communication. Gainesville, FL: Center for Applications of Psychological Type, Inc. p. 13. ISBN 0-935652-77-9.

Zhang, Q., \& Oetzel, J. G. (2006). A cross-cultural test of immediacy-learning models in Chinese classrooms. Communication Education, 55, 313-330.

2005. National Schools of Character: Award Winning Practices. Published and distributed by the Character Education Partnership. 